\title{
Intelligent-Based Maximum Power Extraction on Grid-Integrated Multilevel Inverter-Fed Wind-Driven Induction Generators
}

\author{
B. Meenakshi Sundaram1, B. V. Manikandan², H. Habeebullah Sait ${ }^{3}$ \\ ${ }^{1}$ Department of Electrical and Electronics Engineering, Sethu Institute of Technology, Kariapatti, \\ Tamil Nadu, India \\ ${ }^{2}$ Department of Electrical and Electronics Engineering, Mepco Schlenk Engineering College, \\ Sivakasi, Tamil Nadu, India \\ ${ }^{3}$ Department of Electrical and Electronics Engineering, Anna University, BIT Campus, Tiruchirappalli, \\ Tamil Nadu, India \\ Email: bmsapk@gmail.com, bvmani@mepcoeng.ac.in, habisait@gmail.com
}

Received 28 March 2016; accepted 15 April 2016; published 27 July 2016

Copyright (C) 2016 by authors and Scientific Research Publishing Inc.

This work is licensed under the Creative Commons Attribution International License (CC BY). http://creativecommons.org/licenses/by/4.0/

(c) (i) Open Access

\begin{abstract}
This paper presents an intelligent controller employing Adaptive Neuro-Fuzzy Inference System (ANFIS) for extracting maximum power from the wind energy conversion system even during the change in the wind speed conditions with improved quality of power. The proposed induction generator with multilevel inverter along with intelligent controller based Maximum Power Point Tracking (MPPT) technique aims at integrating winds system with improved maximum power injection and minimum harmonic issues. The proposed method will improve the power quality which is delivered to the grid in terms of harmonic, and inject the maximum power to the grid. To validate the effectiveness of the proposed control strategy, ANFIS controller, Fuzzy Inference System (FIS) and without MPPT controller have been presented and tested using MATLAB/Simulink environment.
\end{abstract}

\section{Keywords}

Wind Energy, Multilevel Inverter, MPPT Technique, ANFIS, FIS, Harmonics 


\section{Introduction}

In the last decade, great increase has been witnessed by the use of renewable energy due to the exhaustion of fossil fuels and different policies of industrial countries with the aim of reducing air pollution [1]. Especially, Wind Energy Conversion Systems (WECS) are considered as one of the most cost-effective solutions than all other renewable sources. In present days, power electronics researchers have been working in multilevel inverters, because of the following features such as: higher voltage operating capability, reduced rate of change of voltage (dv/dt), lower common mode voltages, reduced harmonic content, producing near sinusoidal current, filter of less operation, reduced switching and conduction loss by operating the power switches by fundamental switching which results in increased conversion efficiency. The major problem to harvest more energy from the wind to the grid is the limitation imposed by the ratings of currently available switching devices in the converter. The ratings of the semiconductor devices used in the conventional two-level or three-level VSI topologies do not support the higher power ratings necessary for the grid interface of such large machines. The use of multilevel VSI topology for distributing voltage stress and power losses between a numbers of devices has been well reported [2] [3]. This has motivated designers to go for medium-voltage converters as these are more compact than low-voltage converters for power larger than 1.5 MW [4]. Hence, multilevel inverters are considered as the interface solutions for modern high-power with good quality of power demanding wind-turbine applications [5]. In general, there are two operational modes (fixed speed and variable speed) performed in wind energy conversion system. The variable speed operation has more features such as: reduction in mechanical structure stresses, noise and being easy to control active and reactive power [6]-[8]. In fact, variable speed operation increases the system efficiency and reduces generated power fluctuations [9]. In the operating wind speed range, the turbine shaft's rotational speed should be adjusted optimally with respect to the variable wind speed to extract the maximum power [10]. The features of MPPT are simple and quick tracking under changing condition of output power fluctuations [11] [12]. MPPT algorithms can be broadly classified into sensor based and intelligent based (without sensor) [13].

The algorithms without sensors track the maximum power point by monitoring the power variation. These algorithms are Perturbation and Observation (P\&O) and Incremental Conductance [14] [15]. Neither P\&O nor Incremental Conductance algorithms require any additional sensors to measure wind or rotor speed. But, they have poor dynamic characteristics because they are not usually sensitive to variations in wind speed [16] [17]. Therefore, they are sensitive to modeling uncertainties and may become ineffective in some cases [18].

Most common methods to achieve MPPT in wind turbines are Tip-Speed Ratio (TSR) algorithm, Hill-Climb Searching (HCS) algorithm and the Optimal Torque Control (OTC) [19]. TSR control is used to fix an optimal TSR based on rotor speed. HCS control extracts MPP by searching the peak output power of the wind turbine [20]. The computational intelligence techniques such as fuzzy logic controller, neuro-fuzzy controller and adaptive control techniques are the recent techniques used for the MPPT control [21] [22]. In [23], Wilcoxon Radial Basis Function Network (WRBFN) with HCS, MPPT strategy has been proposed for a variable speed wind turbine systems. Two serious problems associated with the above said controllers are speed efficiency trade off and poor quality output under rapid wind change. This can significantly deteriorate the performance of the grid connected wind energy system.

In this work, ANFIS based approach for controlling the rectifier output and current controller for deriving gating signals for multilevel inverter are presented. The proposed scheme provides a better sinusoidal injection of current into the grid and extracts maximum power from the wind energy conversion system. It is verified with the comparison of other techniques such as fuzzy inference system and without a controller. The paper is organized as follows: mathematical modeling of wind energy conversion with the grid connected system is presented in Section 2. Section 3 explains the FIS control strategy. ANFIS based control strategy is discussed in Section 4. Results and discussions are outlined in Section 6.

\section{Mathematical Model of Wind Energy Conversion with Grid Connected System}

The electrical behavior of the wind turbine is examined by a simplified aerodynamic model. In the proposed grid connected wind power generation system, the Induction Generator [IG] is used because, the advantages of simplicity and absence of separate field circuit can operate with constant and variable speed operational modes and naturally, it protects against short circuit. The structure of the proposed control technique of wind energy system is illustrated in Figure 1. In the proposed wind energy system model, the AC-DC-AC converter has been em- 


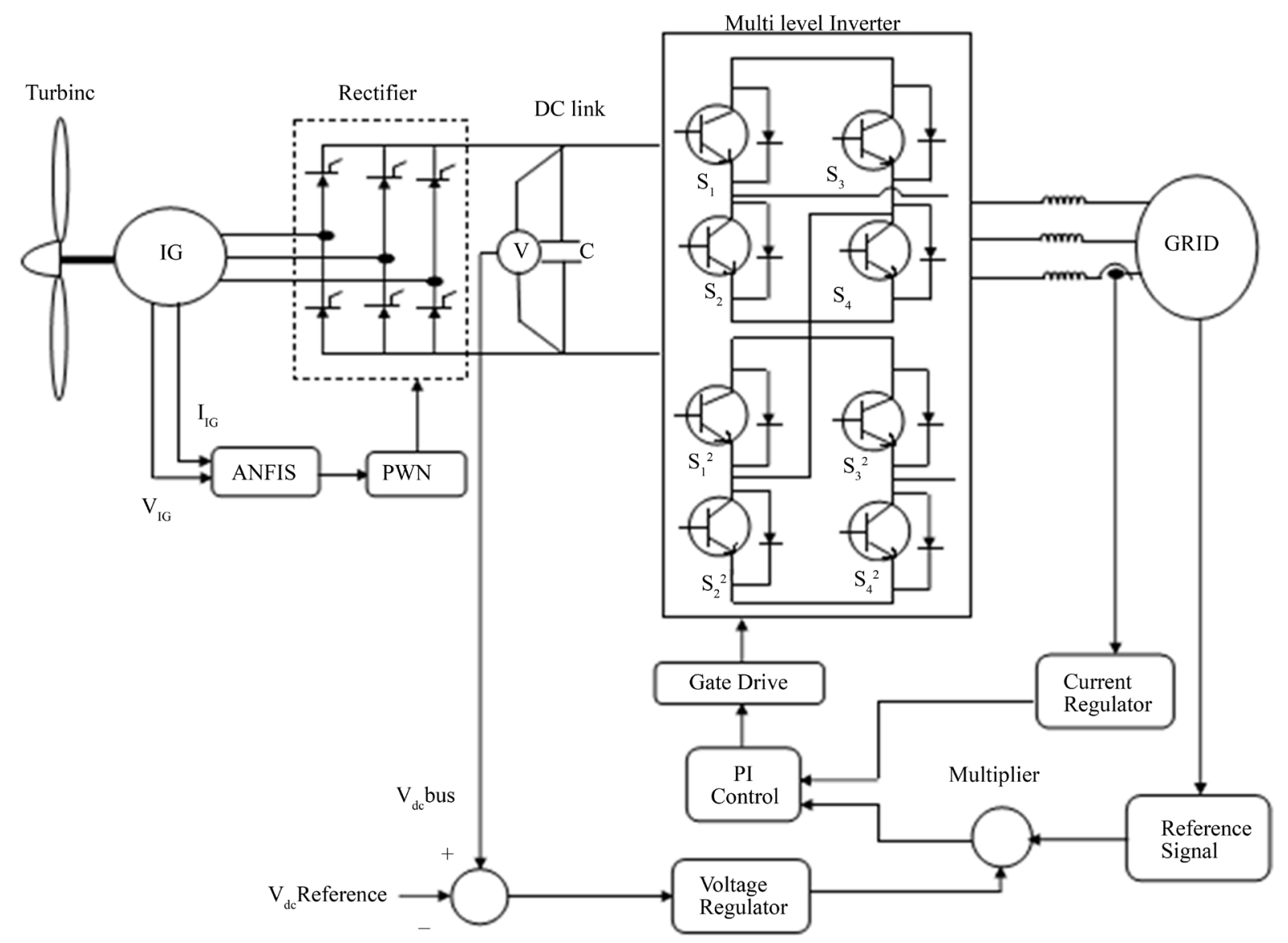

Figure 1. Grid connected wind energy system with the proposed control system.

ployed to enhance the operating performance of the system. The output of variable voltage variable frequency from IG is fed to the controlled rectifier. ANFIS based control scheme has been employed to improve the output performance of the rectifier. The multilevel inverter gate drive pulse is generated by the PI current controller. PI controller is one of the control theory based control techniques and the performance of the controller depends on the controller gain. The inputs of PI controller are the error signal of DC bus voltage and inverter output current. The controlled PWM signal is obtained by a PI current controller, which is applied to the multilevel inverter gate terminals for extracting maximum power and to inject pure sinusoidal current into the grid. So, the conversion performance of the multilevel inverter gets improved.

The detailed description of ANFIS based control is described in Section 4. The DC link voltage is fed to the grid through multilevel inverter and thereby, total harmonic distortion can be reduced.

The mechanical power generated by the wind energy system is derived [24] and presented as follows,

$$
P_{\text {mech }}=C_{p}(\lambda, \beta) P_{\text {wind }}
$$

where $C_{p}$ is power coefficient; $\lambda$ denotes tip speed ratio; $\beta$ is the pitch angle; $P_{\text {wind }}$ represents the available power from wind energy system.

The available power of the wind energy system is illustrated as,

$$
P_{\text {wind }}=\frac{1}{2} \rho S V_{\text {wind }}^{3}
$$

where $\rho$ is the air density $\left(\mathrm{kg} / \mathrm{m}^{3}\right) ; \quad S$ denotes area of wind wheel $\left(\mathrm{m}^{2}\right) ; \quad V_{\text {wind }}$ is the wind speed $(\mathrm{m} / \mathrm{s})$.

In IG model, the output power extracting equation is needed to analyze the energy conversion of wind system. The real and reactive power flow of IG is derived in terms of voltage, flux, synchronous speed and stator resistance of the system. The real and reactive power flow equations of IG are given below, 
Real power,

$$
P_{s}=-\frac{3}{2} \frac{\omega_{s} \psi_{s} M}{L_{s}} i_{q r}
$$

Reactive power,

$$
Q_{s}=\frac{3}{2} \frac{\omega_{s} \psi_{s}}{L_{s}}\left(\psi_{s}-M i_{d r}\right)
$$

where $\omega_{s}$ is the synchronous speed;

$M$ is the magnetizing inductance $(\mathrm{H})$;

$\psi_{s}$ is the stator flux;

$L_{s}$ is the stator per phase inductance $(\mathrm{H})$;

$i_{q r}$ and $i_{d r}$ are the q-axis and d-axis rotor current, respectively.

The Total Harmonic Distortion (THD) of the system is expressed as follows,

Voltage THD,

$$
V_{T H D}=\sqrt{\sum \frac{V_{n}^{2}}{V_{1}}}
$$

Current THD,

$$
I_{T H D}=\sqrt{\sum \frac{I_{n}^{2}}{I_{1}}}
$$

where $V_{n}$ and $I_{n}$ are the $n^{\text {th }}$ harmonic voltage and current; $V_{1}$ and $I_{1}$ are the fundamental voltage and current respectively.

The real and reactive power flow of the wind energy system to $b^{\text {th }}$ bus of the grid connected system can be represented as follows,

$$
\begin{gathered}
P_{\text {grid }}=\frac{V_{s} V_{b} \sin \theta_{b}}{X_{b}} \\
Q_{\text {grid }}=\frac{V_{s}^{2}-V_{s} V_{b} \cos \theta_{b}}{X_{b}}
\end{gathered}
$$

where $V_{s}$ is the stator voltage of IG; $V_{b}$ and $\theta_{b}$ are the voltage magnitude and angle of $b^{\text {th }}$ bus; $X_{b}$ is the reactance of the line.

\section{Wind Power Characteristics}

Figure 2 illustrates the mechanical power of a wind turbine versus the rotor speed at different wind velocities. Each and every point of the blade receives different values of wind speed. The mechanical power developed by the wind turbine not only depends on the wind speed (which is difficult to measure) and also depends on the air density and the turbine performance coefficient. According to the ideal gas law, the density of a gas is proportional to its pressure and inversely proportional to its temperature as in (9).

$$
\rho=\frac{M \cdot P}{R \cdot T}
$$

where $P$ is the absolute pressure, $M$ is the molar mass, $R$ is the gas constant $\left(8.314472 \mathrm{~J} \cdot \mathrm{K}^{-1} \cdot \mathrm{mol}^{-1}\right)$, and $T$ is the absolute temperature. If the pressure increases by $10 \%$, the temperature decreases by $15 \%$ and the air density will increase about 30\%. The power co-efficient and the efficiency of wind turbine are the function of the tipspeed ratio. In general, wind turbine must be operating at the maximum value of power co-efficient at all wind speeds. The above said problem has been eliminated by FIS and ANFIS based MPPT control strategy. 


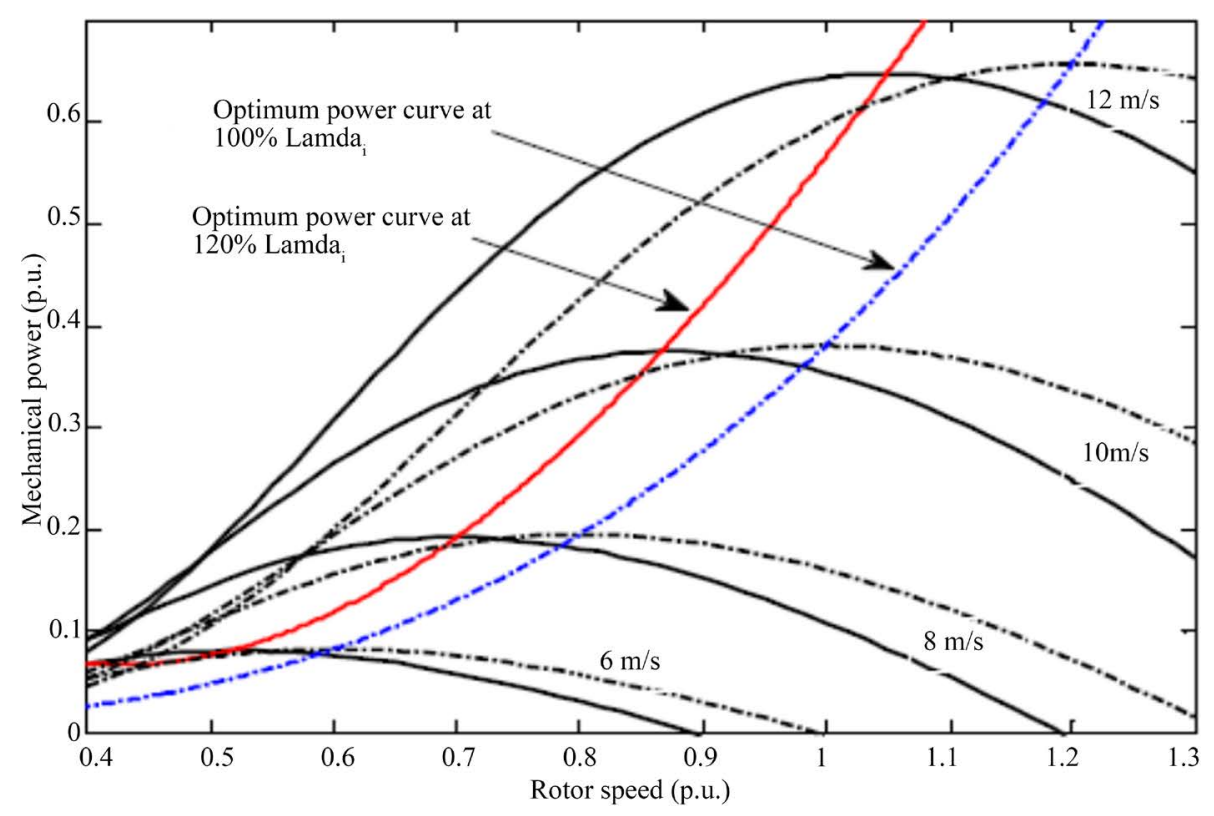

Figure 2. Change in rotor speed with mechanical power.

\section{FIS Based Control Strategy for Rectifier Control}

Fuzzy Inference System is a multidisciplinary computing technique based on the concepts of fuzzy set theory, fuzzy if then rules and fuzzy reasoning. The applications of FIS in a wide variety of areas like automatic control, decision analysis and time series prediction. With crisp input and outputs, a fuzzy inference system implements a non linear mapping from its input space to output space. This mapping is accomplished by a number of fuzzy if then rules, each of which describes the behavior of the mapping.

In this paper, FLC has been employed for extraction of maximum power at different wind speed to operate the wind turbine at maximum torque condition. The inputs of the FLC are error and change in error. The error value has been derived from the electrical parameters of the induction generator (voltage and current).

Figure 3 indicates the structure of the input membership function used in FLC for the proposed work. Here, the triangular and trapezoidal membership functions were utilized. The error value lies in the range of -1 to 1 , which is represented as linguistic terms (Negative Big, Negative Small, Zero, Positive Small, Positive Big). The proposed FLC tuned by $5 \times 5$ rules for providing the required duty cycle $(\Delta D)$ for controlling the operation of the rectifier. The rule based MPPT algorithm is presented in Table 1.

The result of the defuzzification has to be a numeric value which determines the change of duty cycle of the PWM signal used to drive the Switch.

Cluster 1: When induction generator voltage and current are negative big or negative small, the firing angle of the rectifier should be negative big or negative small in order to maintain the DC link voltage at the rated value.

Cluster 2: When induction generator voltage and current are zero, the firing angle of the rectifier should be zero in order to maintain the DC link voltage at the rated value.

Cluster 3: When induction generator voltage and current are positive small or positive big, the firing angle of the rectifier should be positive big or small in order to maintain DC link voltage at the rated value.

There are many methods to calculate the crisp output of the system. Centre of Gravity (CoG) method is used in the proposed system because it gives better results. In the present work, the CoG is expressed mathematically as $\Delta D$ given in (10).

$$
\Delta D=\frac{\sum_{n=1}^{4} Y[i] \times F[i]}{\sum_{n=1}^{4} Y[i]}
$$

where $Y[i]$ is the $i$ th member of the output vector and $F[i]$ are the multiplying coefficients of the output mem- 


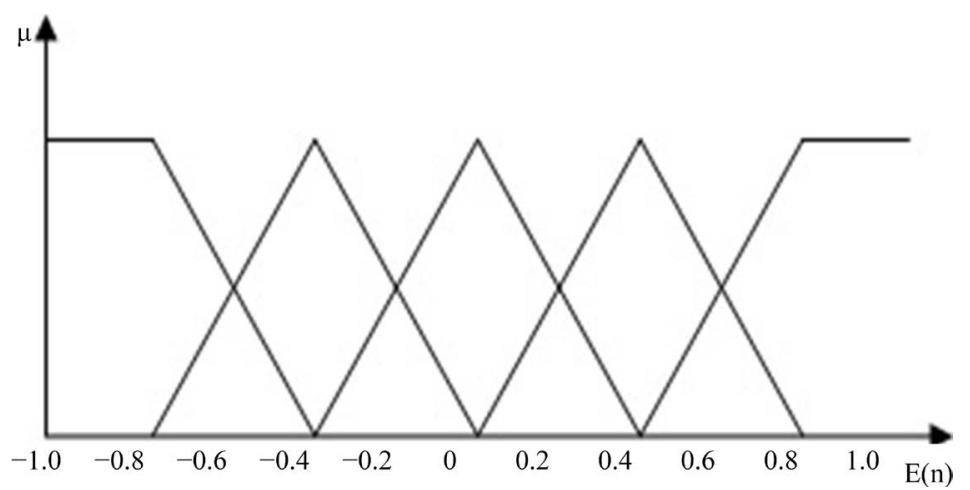

Figure 3. Input membership function of FLC.

Table 1. Fuzzy rule base table.

\begin{tabular}{ccccccc}
\hline \multicolumn{1}{c}{$\mathbf{E}$} & NB & NS & ZE & PS & PB & Cluster 1 \\
\hline NB & -1 & -0.5 & -0.5 & 0 & 0 & Cluster 2 \\
NS & -0.5 & -0.5 & -0.5 & 0 & 0.5 & Cluster 3 \\
ZE & -0.5 & -0.5 & 0 & 0.5 & 0.5 & 1 \\
PS & -0.5 & 0 & 0.5 & 0.5 & 1 & 0.5 \\
PB & 0 & 0 & 0.5 & & & \\
\hline
\end{tabular}

bership function as shown in Table $1 . \Delta D$ is the change of duty cycle and this number represents a signed number which is added or subtracted from the present duty cycle to generate the next system response for reaching the MPP as given by (11).

$$
D_{\text {new }}=D_{\text {old }}+\Delta D
$$

Fuzzy system output presented in surface plot which is shown Figure 4 for a change in duty cycle of rectifier for an inputs of different error and change of error.

\section{ANFIS Based Control Strategy for PWM Pulses Applied to Rectifier}

ANFIS holds the benefits of both neural network and fuzzy logic controller. In ANFIS, the fuzzy inference system is implied through the structure and neurons of the feed forward adaptive neural network. In the proposed control, the data set is developed by neural network in terms of voltage $\left(V_{I G}\right)$, current $\left(I_{I G}\right)$ as inputs and PWM control pulses $\left(I_{g}\right)$ as output. Fuzzy control rules are designed by using the generated data set. The adaptive system is developed through training and testing of input-output data. In the proposed approach, the voltage and the current of the IG are generated in the form of vector and the data are applied to the neural network. The testing of ANFIS is executed for providing exact output as same as speed control of IG.

The structure of ANFIS system consists of five layers which are categorized as the input layer, input membership function layer, rule layer, output membership function layer and output layer. The first order two input Sugeno fuzzy model is employed and it is given in Figure 5.

The typical fuzzy if-then rule set for the first order Sugeno fuzzy inference model can be stated as follows,

$$
\begin{aligned}
& \text { IF } x_{1} \text { is } A_{1} \text { AND } x_{2} \text { is } B_{1} \text { THEN } f_{1}=p_{1} V_{I G}+q_{1} I_{I G}+r_{1} \\
& \text { IF } x_{1} \text { is } A_{2} \text { AND } x_{2} \text { is } B_{2} \text { THEN } f_{2}=p_{2} V_{I G}+q_{2} I_{I G}+r_{2}
\end{aligned}
$$

where $A_{i}$ and $B_{i}$ are the antecedent fuzzy sets and parameters $p_{i}, q_{i}, r_{i}$ are the fuzzy design parameters calculated during the training process $(i=1,2, \cdots, n)$. It is shown in Figure 7 . The mechanism for obtaining the control pulses of rectifier for a given input vector $\left[V_{I G}, I_{I G}\right]$ through ANFIS structure is shown in Figure 6. The PWM control signal generation for rectifier based on the weight function is given below; 


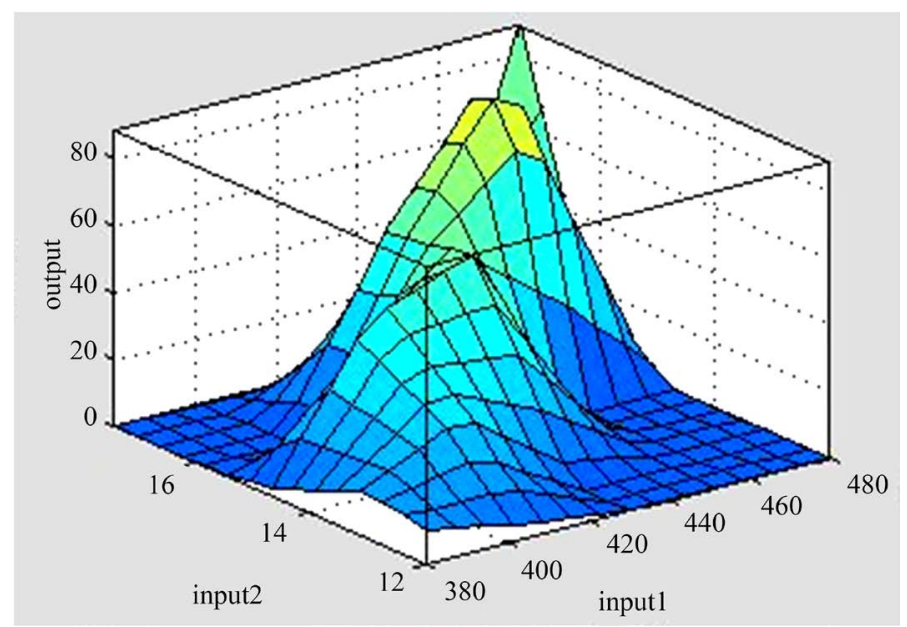

Figure 4. Surface plot response of FLC.
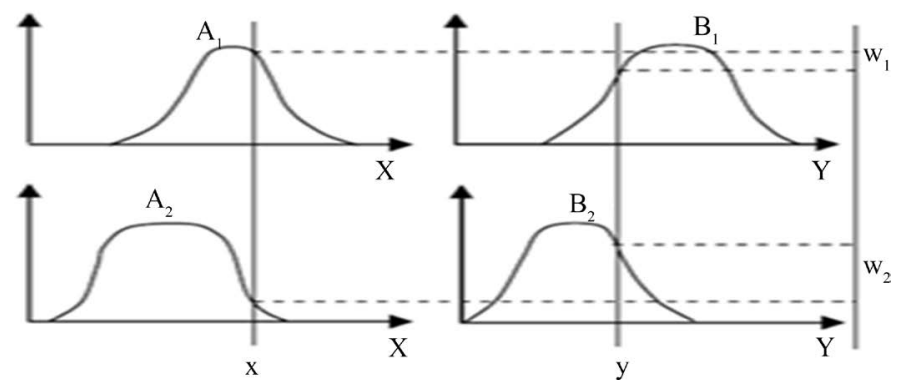

Figure 5. Two input first order Sugeno fuzzy model with two rules.

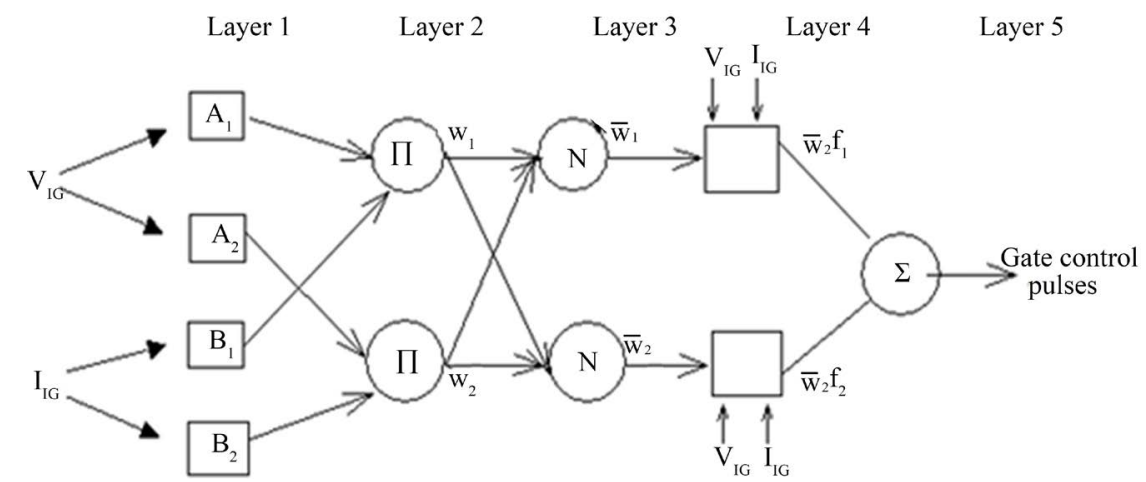

Figure 6. Structure of ANFIS.

$$
I_{g}=\frac{w_{1} f_{1}+w_{2} f_{2}}{w_{1}+w_{2}}=\bar{w}_{1} f_{1}+\bar{w}_{2} f_{2}
$$

The circular nodes represent nodes that are fixed; whereas the square nodes are nodes that have parameters to be learnt. The structure of the ANFIS and each layer are explained below.

Layer 1: In this layer, the adaptive nodes with node functions are included; the node function is defined and given in Figure 6.

In Figure 6, $V_{I G}$ is the input to the node $i \& A_{i}$ is the linguistic label related to that node function. The membership function $O_{i}^{\text {layer1 }}$ indicates the extent to which the specified $I_{I G}$ satisfies the quantifier $A_{i}$. Generally, a bell-shaped function $\mu_{A_{i}}\left(V_{I G}\right)$, which has a maximum of 1 and a minimum of 0 , is considered. It is represented below. 


$$
\mu_{A_{i}}\left(V_{I G}\right)=\frac{1}{1+\left|\frac{V_{I G}-c_{i}}{a_{i}}\right|^{2 b_{i}}}=\exp \left\{-\left(\frac{V_{I G}-c_{i}}{a_{i}}\right)^{2 b_{i}}\right\}
$$

where the parameter set $\left\{a_{i}, b_{i}, c_{i}\right\}$ which modifies the membership functions on the linguistic label $A_{i}$ is known as premise parameter. Similarly, the value of $\mu_{B_{i}}\left(I_{I G}\right)$ is selected.

Layer 2: Every node in this layer is fixed. This is where the t-norm is used to "AND", the membership grades (for example- the product). The firing strength of the rule is calculated as

$$
O_{i}^{\text {layer } 2}=w_{i}=\mu_{A_{i}}\left(V_{I G}\right) \mu_{B_{i}}\left(I_{I G}\right), i=1,2
$$

Layer 3: The $i^{\text {th }}$ node of this layer is used to determine the ratio between the firing strength of the $i^{\text {th }}$ rule and the sum of firing strength of all rules. It is referred as normalized firing strength.

$$
O_{i}^{\text {layer } 3}=\bar{w}_{i}=\frac{w_{i}}{w_{1}+w_{2}}, \quad i=1,2
$$

Layer 4: The nodes in this layer are adaptive and perform the consequent of the rules,

$$
O_{i}^{\text {layer } 4}=\bar{w}_{i} f_{i}=\bar{w}_{i}\left(p_{i} V_{I G}+q_{i} I_{I G}+r_{i}\right)
$$

where $\bar{w}_{i}$ is the output layer 3 and $\left\{p_{i}, q_{i}, r_{i}\right\}$ are the parameter set of the layer 3 . The term consequent parameters are used to indicate the parameters of this layer.

Layer 5: By taking the summation of all the inputs by the single node that exists in this layer indicated as $\Sigma$, the overall output is calculated.

Overall output,

$$
O_{i}^{\text {layer } 5}=\sum_{i} \bar{w}_{i} f_{i}=\frac{\sum_{i} w_{i} f_{i}}{\sum_{i} w_{i}}
$$

The overall output $I_{g}$ can be expressed as a linear combination of the consequent parameters for the case of fixed premise parameters. The output of Figure 6 can be represented more precisely as,

$$
I_{g}=\bar{w}_{1} f_{1}+\bar{w}_{2} f_{2}
$$

In the proposed control system, the ANFIS is trained by giving the voltage vector and the current vector of IG as inputs which determine the desired PWM control pulses for rectifier. Thereby, maximum power can be extracted from IG. Figure 7 shows the training data for the ANFIS controller. Initially an input-output membership function and 25 fuzzy rule set have to be invoked from the grid partition of ANFIS concept.

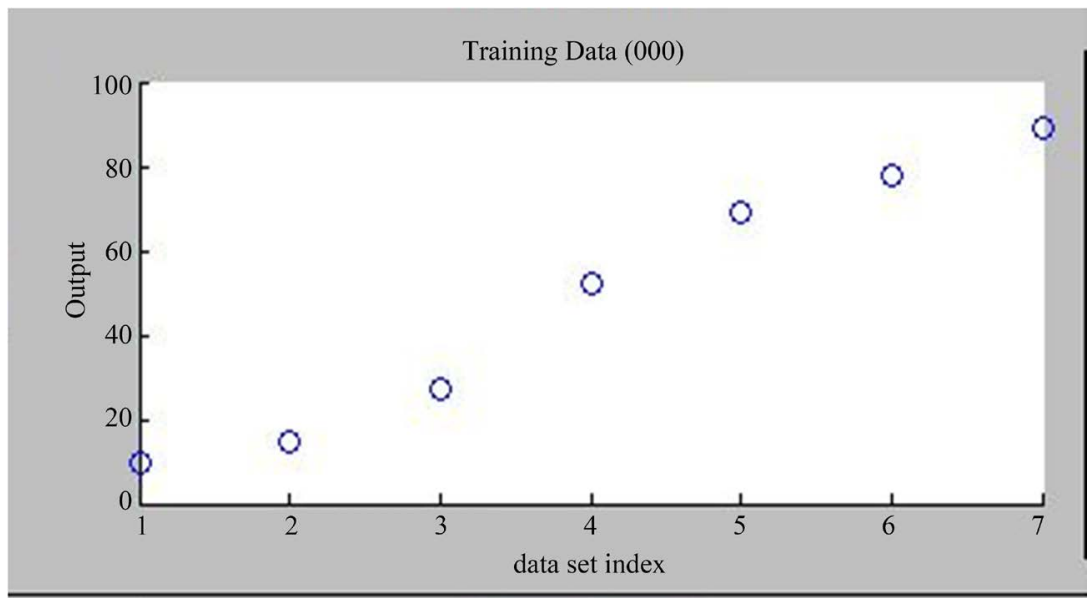

Figure 7. Training data for ANFIS controller. 
After generating the initial input membership function and fuzzy rules based on the training data, fuzzy inference system is trained by the hybrid learning algorithm of neural network. One hundred epochs have been considered for training and Figure 8 shows training error at the end of training. From the training error plot, it is evident that the fuzzy inference system has been well trained with help of neural network with minimum error of 1.24. Figure 9 shows the testing of trained data with test data. The proposed ANFIS model structure is shown in Figure 10.

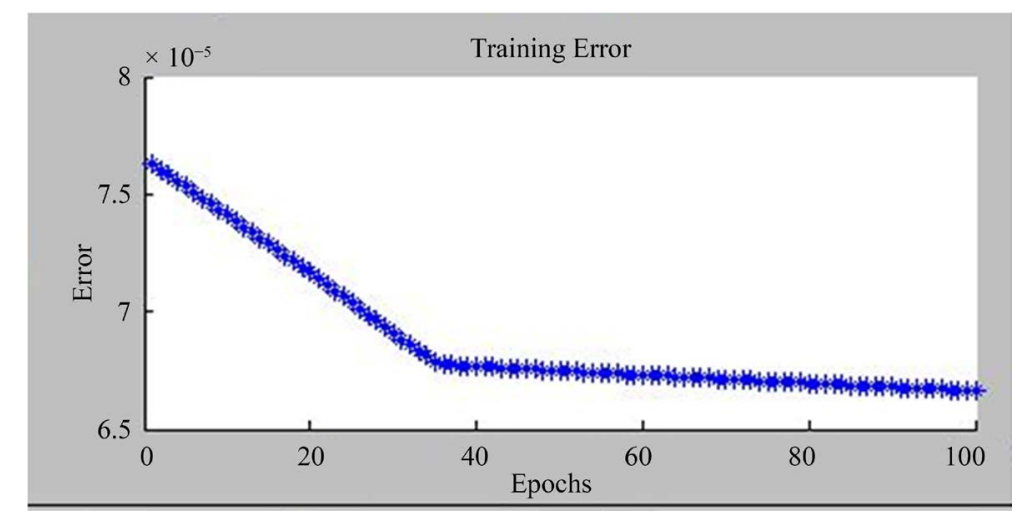

Figure 8. Training error plot.

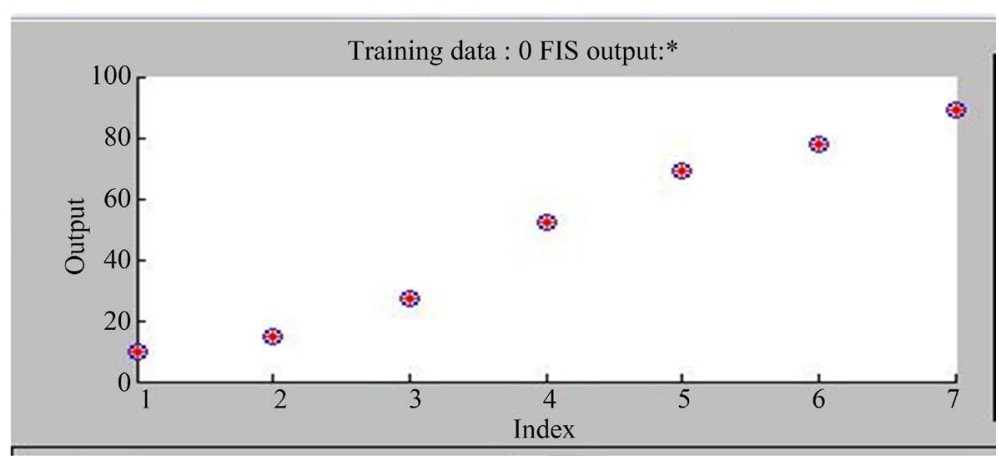

Figure 9. Testing of trained data with test data.

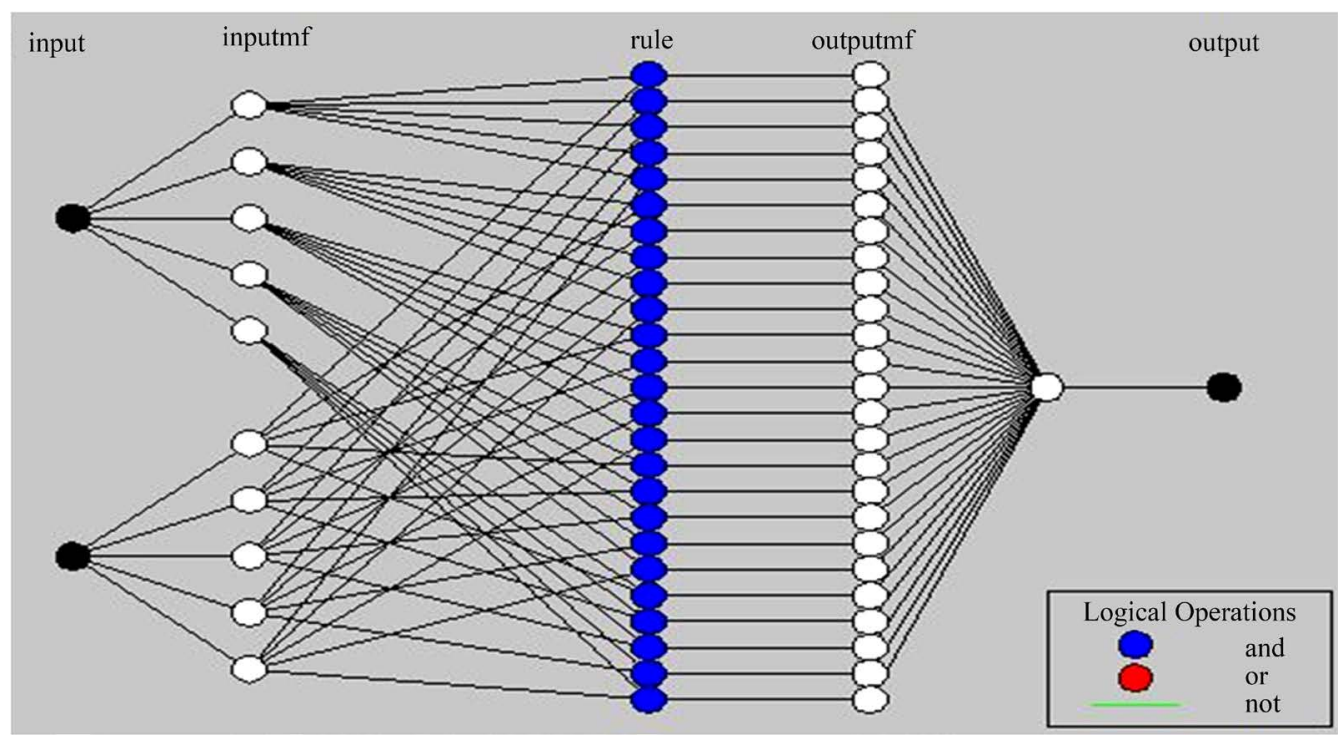

Figure 10. ANFIS model structure for grid connected wind energy system. 
The structure consists of five layers. First layer is the input layer and the inputs are error and the rate of change of error. Next layer is the input membership function layer where inputs are distributed with five fuzzy sets. Third layer is the rule layer where the inputs and outputs are linked with AND operator. Fourth layer is the output membership function layer where the output is distributed with ten constant values. Last layer is the output layer which sums up all the inputs coming from the previous layer and transforms the fuzzy classification results in to a crisp value.

\section{Results and Discussion}

The proposed MPPT based control technique has been implemented in MATLAB environment and the performances are evaluated. The proposed MPPT controller performance is tested with an Induction Generator model with rating $480 \mathrm{~V}, 275 \mathrm{KW}$. IG current and voltage are applied to ANFIS and the control output is obtained. Based on the control output, the PWM pulse is generated to control the operation of the rectifier. The PI current controller provides switching signals for a multilevel inverter to reduce the harmonic distortion in the output. The operation of the PI current controller is based on the DC link voltage, grid current, and grid voltage.

The voltage from the IG, rectifier voltage, inverter output voltage and current injected to the grid and current harmonics are evaluated at different wind speed. The output voltage of the Induction Generator and the current injected by the inverter to the grid system are shown in Figure 11 and Figure 12. For the considered wind speed of $6 \mathrm{~m} / \mathrm{sec}$, real power injected into the grid and the reactive power consumption have been illustrated in Figure 13 and Figure 14. Figure 15 and Figure 16 describe the output voltage of the controlled rectifier and multilevel inverter.

The harmonics are evaluated at different wind speed such as $6 \mathrm{~m} / \mathrm{s}, 8 \mathrm{~m} / \mathrm{s}, 10 \mathrm{~m} / \mathrm{s}, 12 \mathrm{~m} / \mathrm{s}$, and $14 \mathrm{~m} / \mathrm{s}$, respectively. The performance of the proposed (ANFIS and PI) control strategy is compared with the existing control strategy. The maximum power extraction with the change in wind speed of $6 \mathrm{~m} / \mathrm{s}$ and $14 \mathrm{~m} / \mathrm{s}$ has been tested for different control strategies. It is shown in Figure 17. It is found that the proposed control strategy has extracted maximum power compared to the existing strategy. The Maximum Power extracted at different wind speed is tabulated in Table 2.

The measurement of harmonics is used to analyze the performance of the proposed control strategy [25]. The current harmonic spectrum of the wind speed of $6 \mathrm{~m} / \mathrm{s}$ has been analyzed for different control strategies and they are presented in Figures 18(a)-(c). Similarly, the current THD for different wind speed is analyzed and tabulated in Table 3.

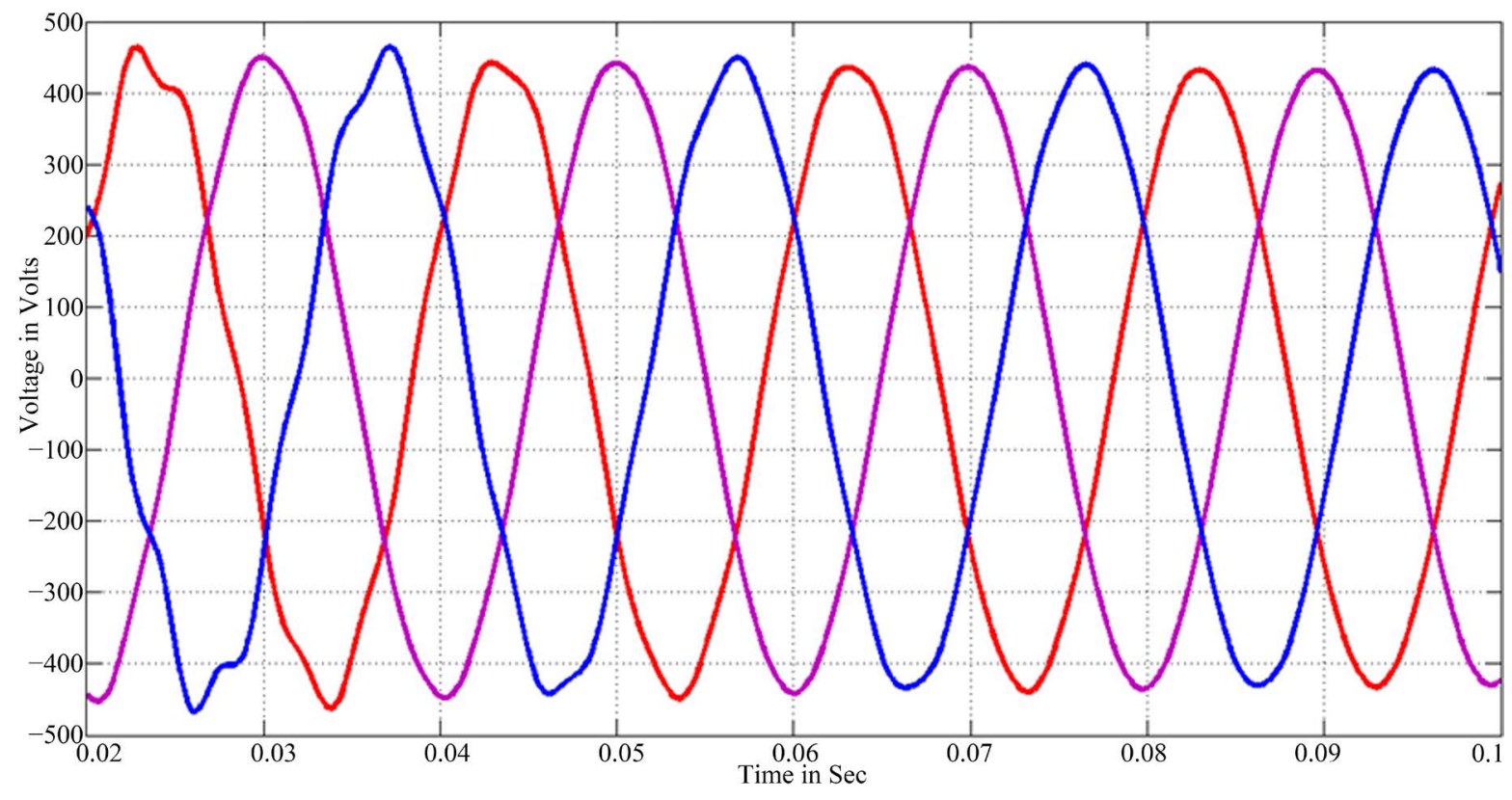

Figure 11. Output voltage of the induction generator. 


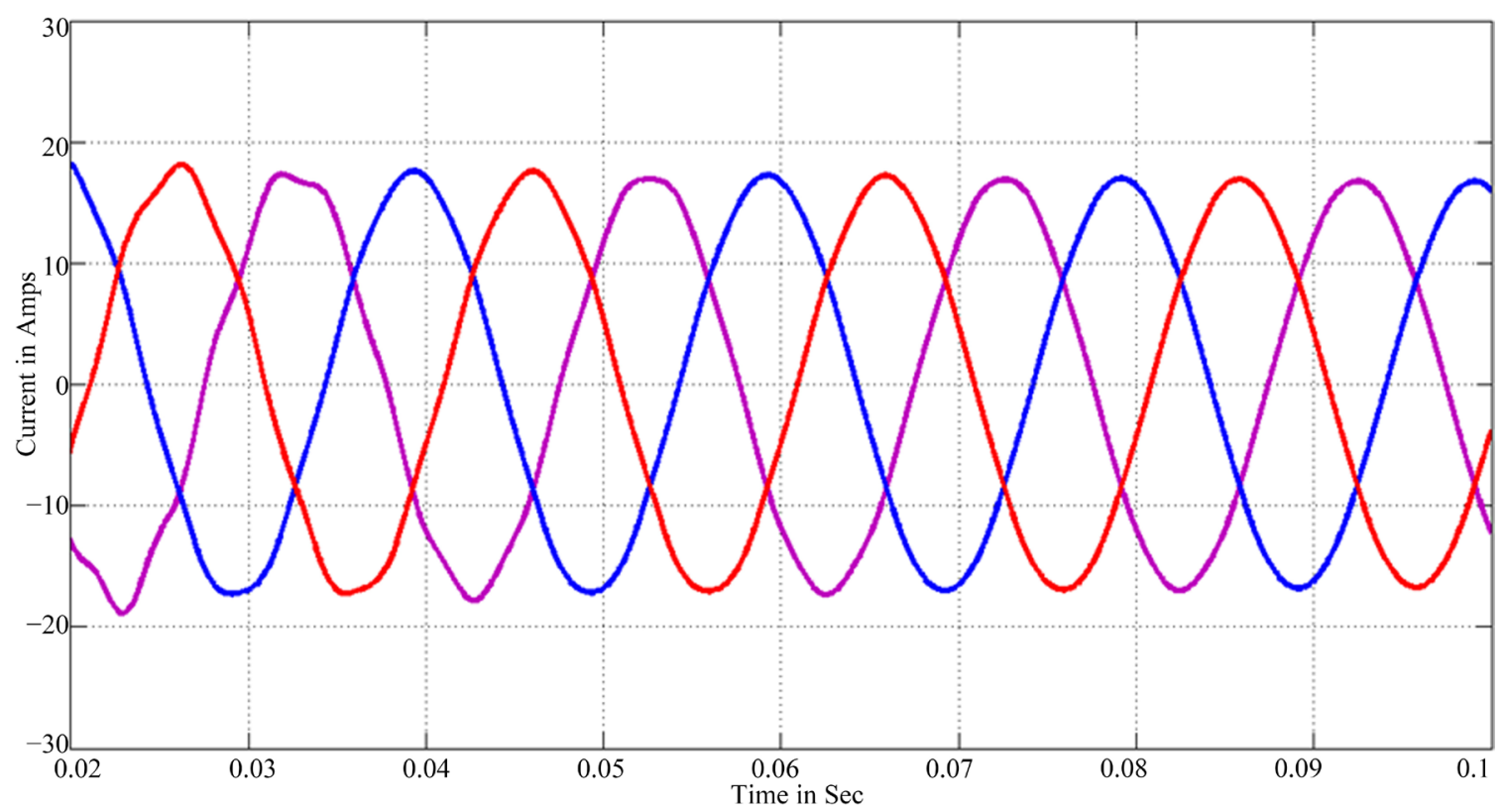

Figure 12. Injected inverter current to the grid.

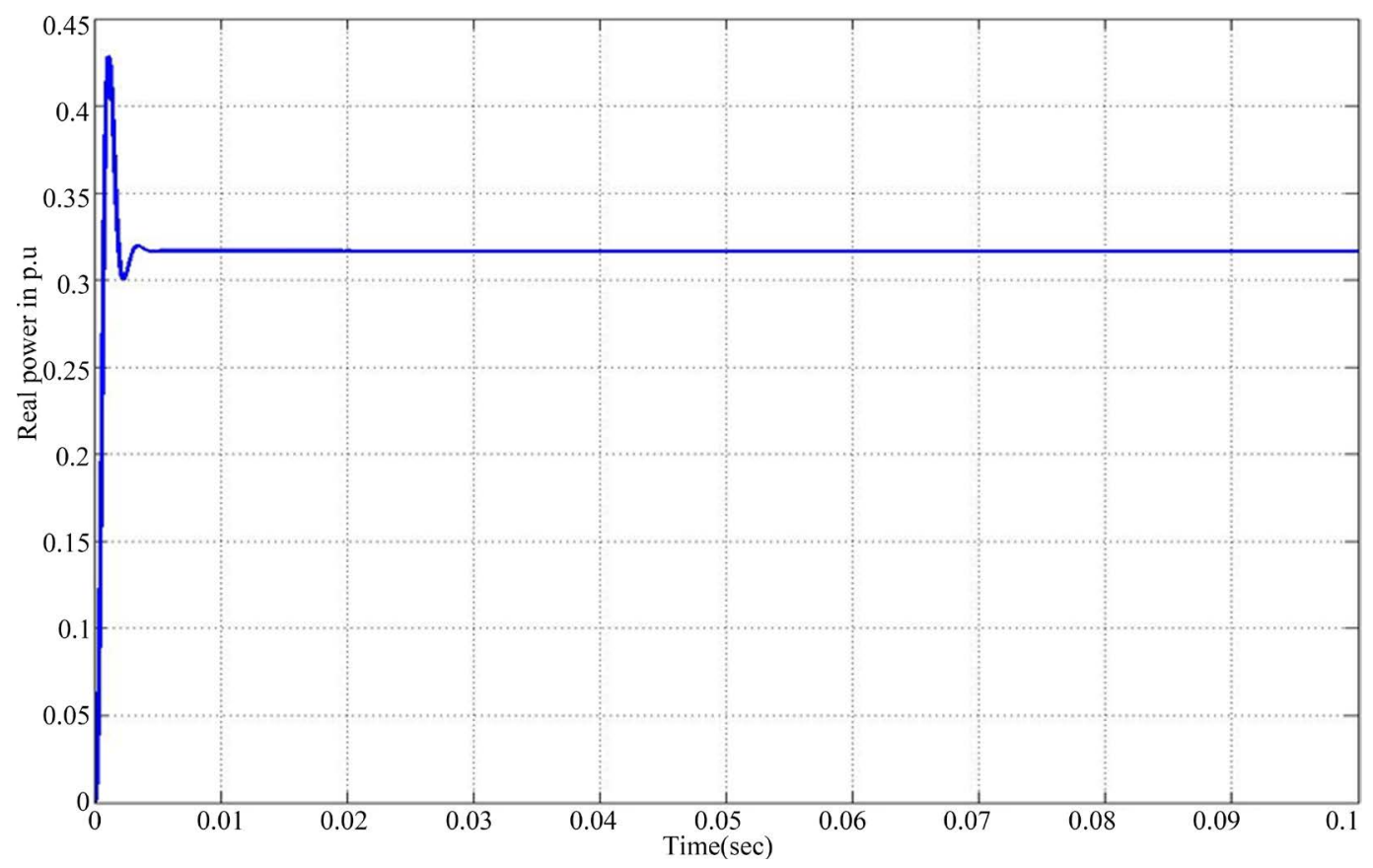

Figure 13. Real power injected to the grid at a wind speed of $6 \mathrm{~m} / \mathrm{sec}$.

Table 2. Maximum power at different wind speed.

\begin{tabular}{cccc}
\hline \multirow{2}{*}{ Wind speed (m/sec) } & \multicolumn{3}{c}{ Maximum power $(\mathbf{K W})$} \\
\cline { 2 - 4 } & Without MPPT strategy & Fuzzy control strategy & Proposed ANFIS based control strategy \\
\hline 6 & 78.45 & 80.75 & 82.5 \\
8 & 128.8 & 132.54 & 135.7 \\
10 & 177.59 & 182.34 & 189.6 \\
12 & 215.49 & 220.65 & 229.8 \\
14 & 260.89 & 265.25 & 274.5 \\
\hline
\end{tabular}




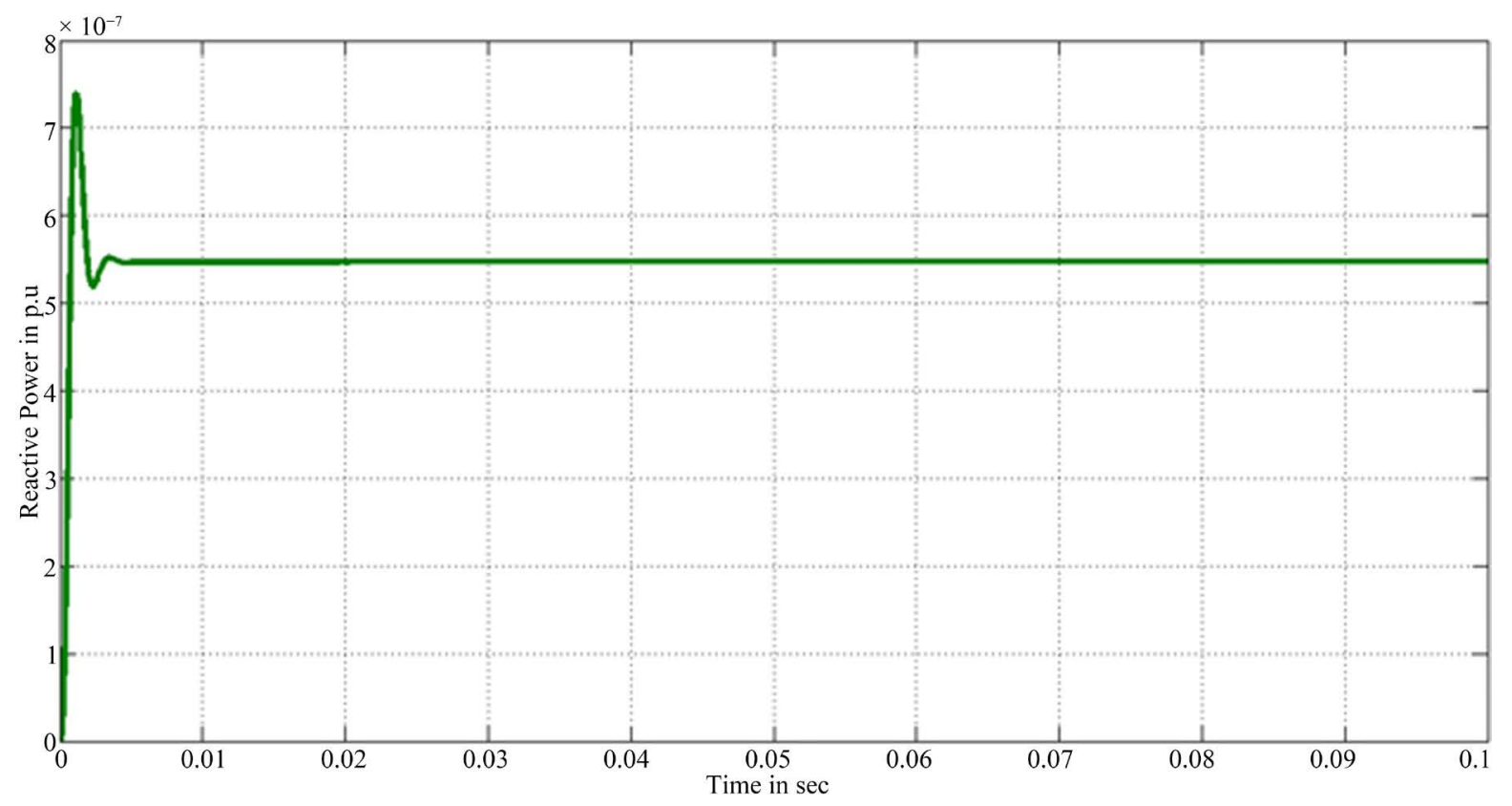

Figure 14. Reactive power consumption at a wind speed of $6 \mathrm{~m} / \mathrm{sec}$.

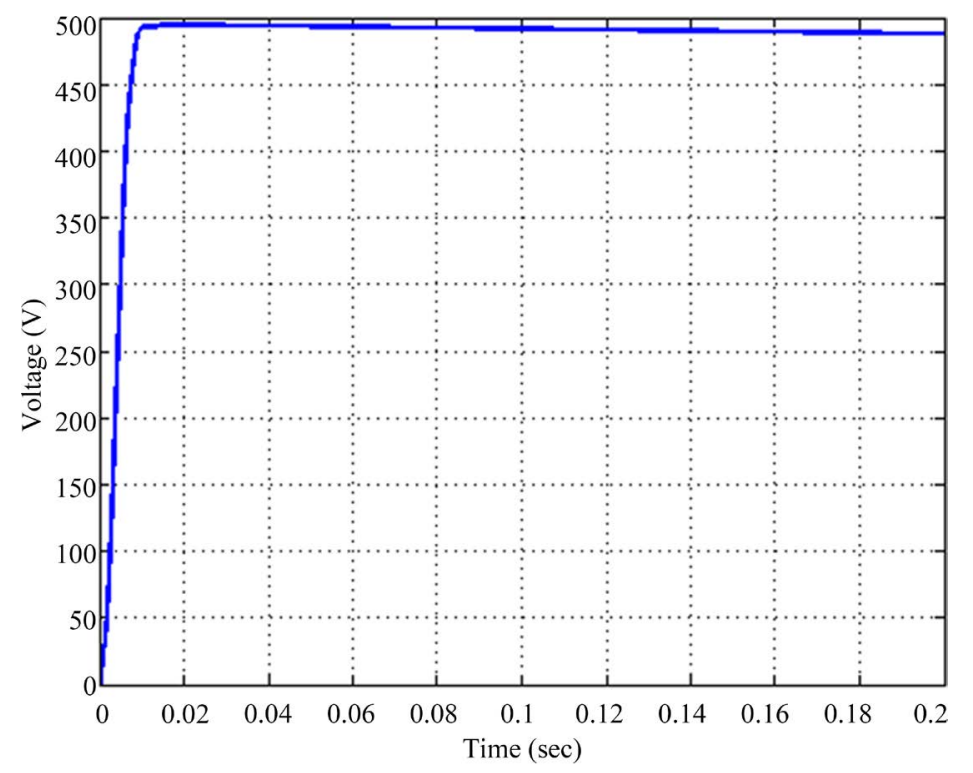

Figure 15. Output voltage of the controlled rectifier.

Table 3. Current harmonics at different wind speed.

\begin{tabular}{cccc}
\hline \multirow{2}{*}{ Wind speed $(\mathbf{m} / \mathbf{s e c})$} & \multicolumn{3}{c}{ Current THD in \% } \\
\cline { 2 - 4 } & Without MPPT strategy & Fuzzy control strategy & Proposed ANFIS based control strategy \\
\hline 6 & 10.94 & 9.65 & 4.62 \\
8 & 10.93 & 9.16 & 4.60 \\
10 & 9.63 & 9.10 & 4.50 \\
12 & 8.89 & 8.39 & 3.69 \\
14 & 8.31 & 8.20 & 3.17 \\
\hline
\end{tabular}




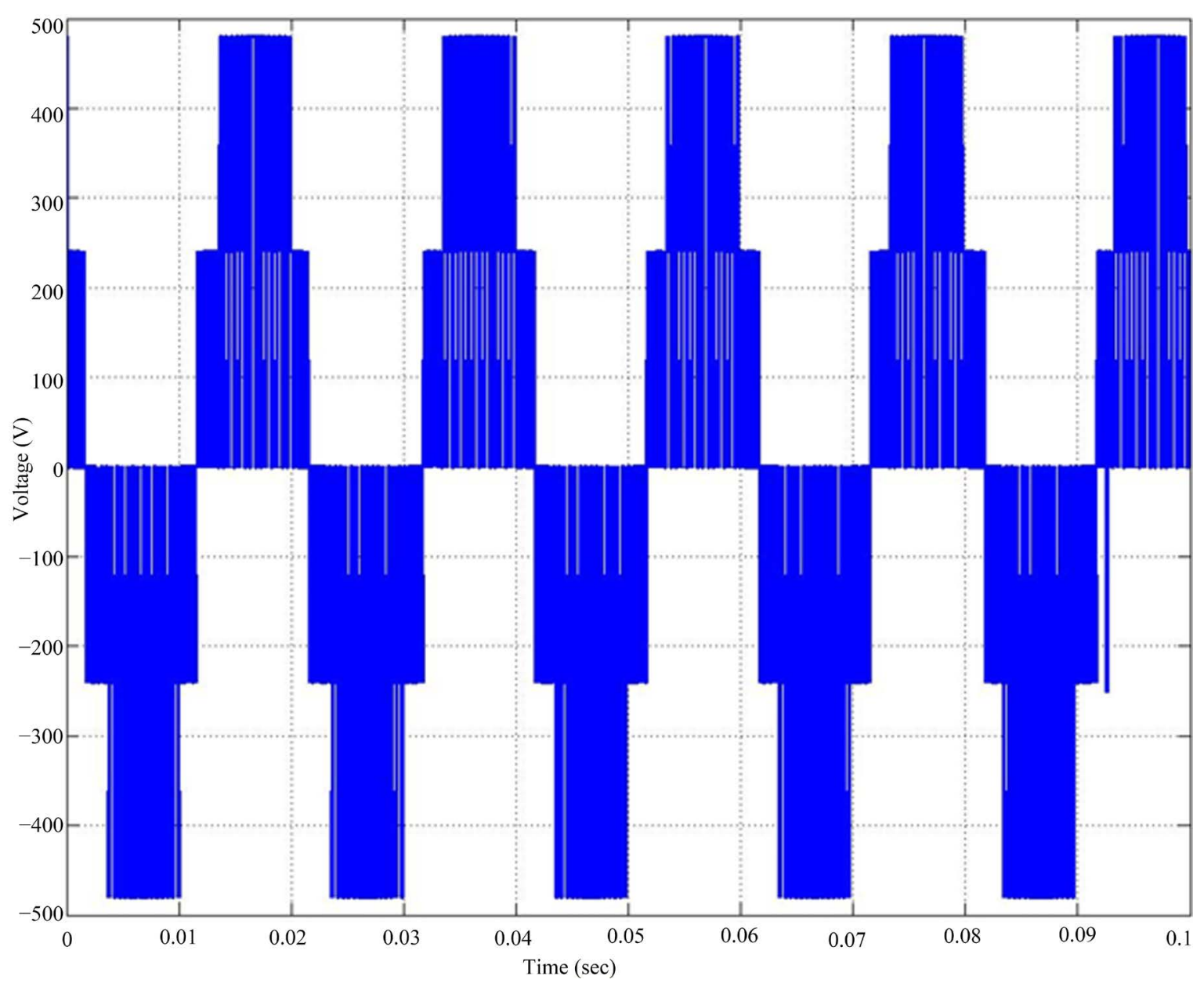

Figure 16. Output voltage of the multilevel inverter.

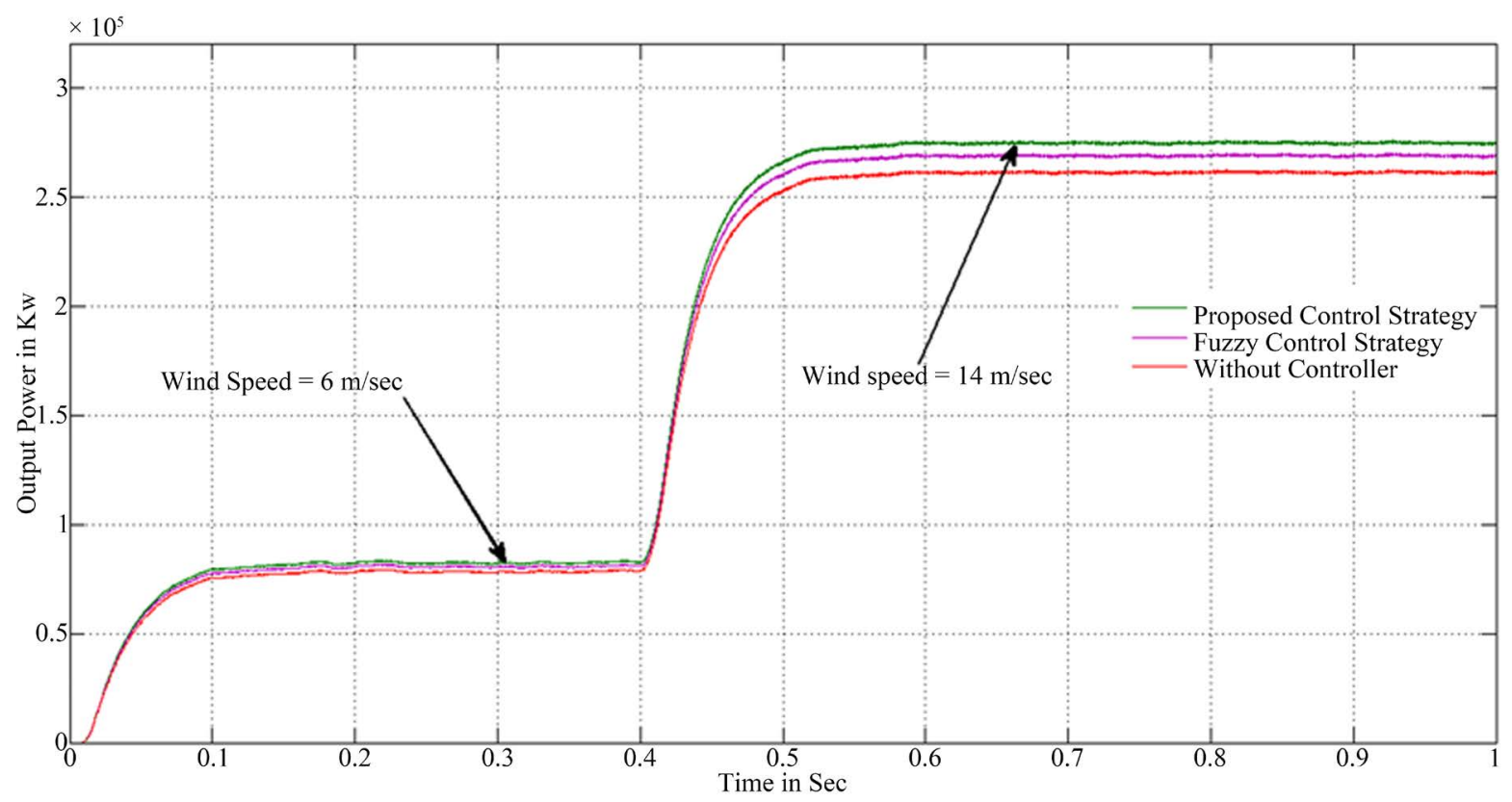

Figure 17. Maximum power at wind speed of $6 \mathrm{~m} / \mathrm{s}$ and $14 \mathrm{~m} / \mathrm{s}$ for different control strategies. 


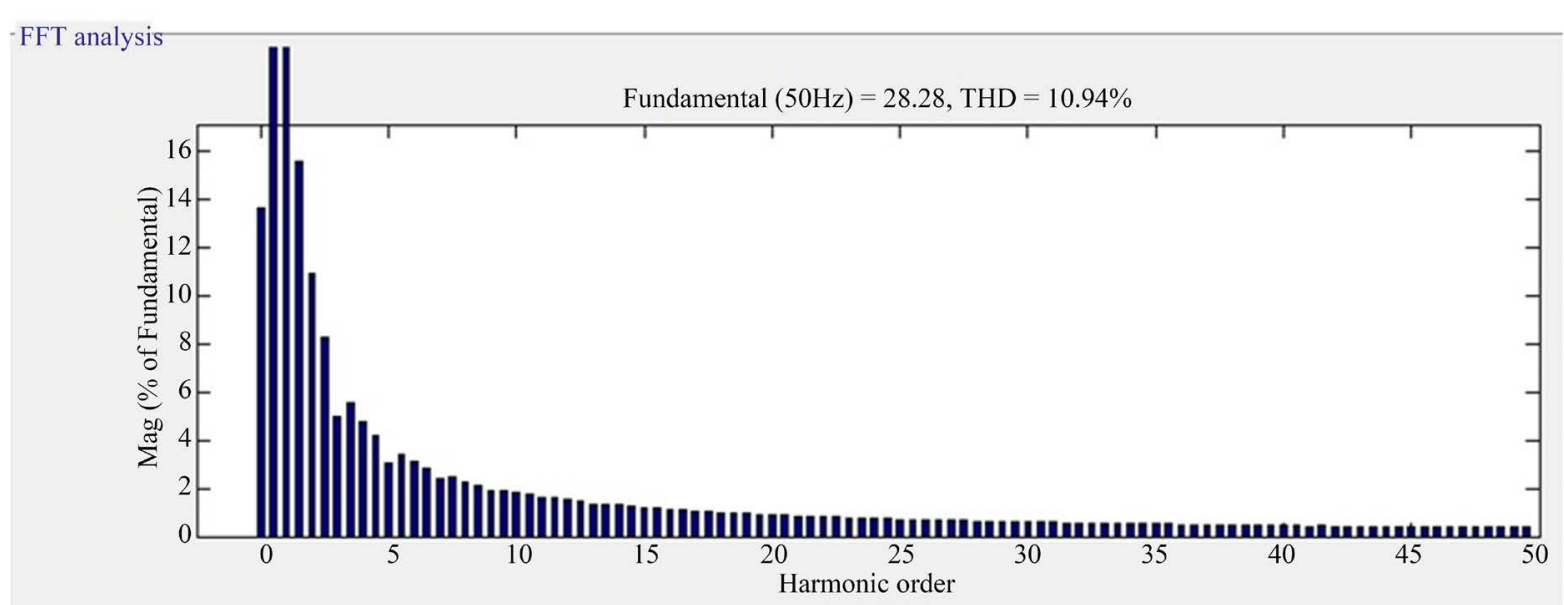

(a)

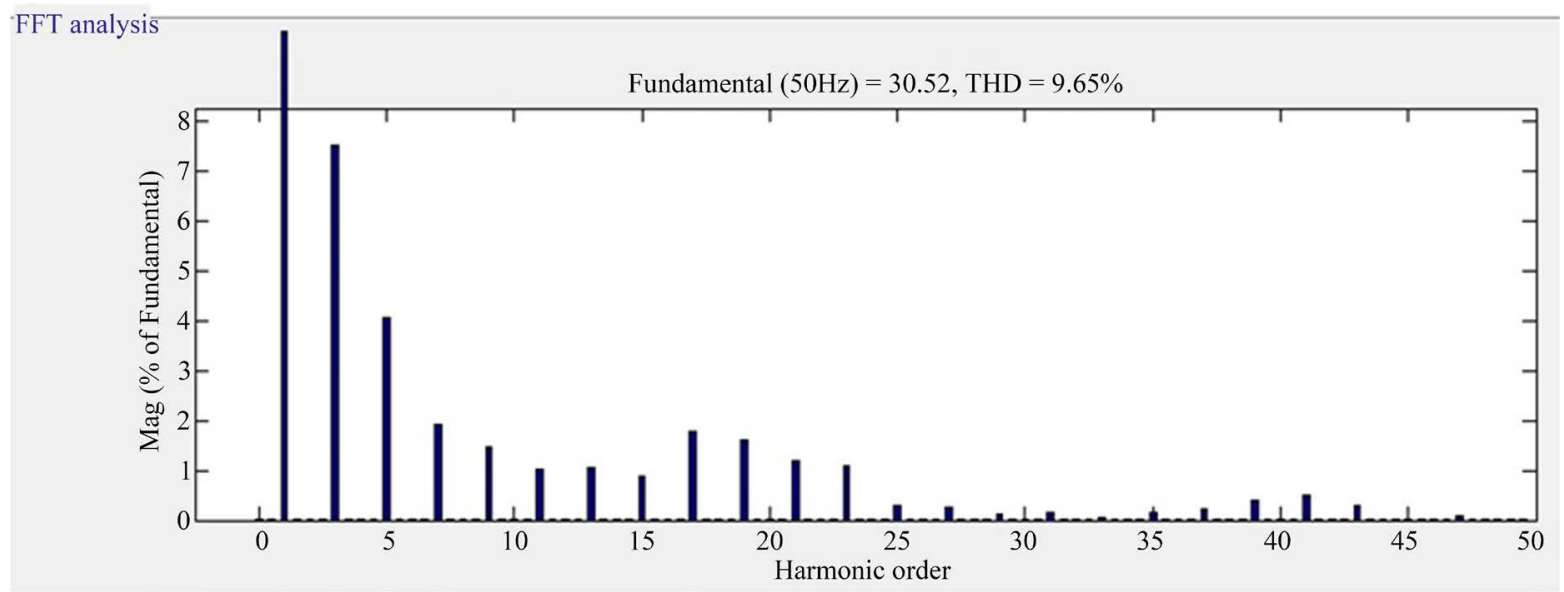

(b)

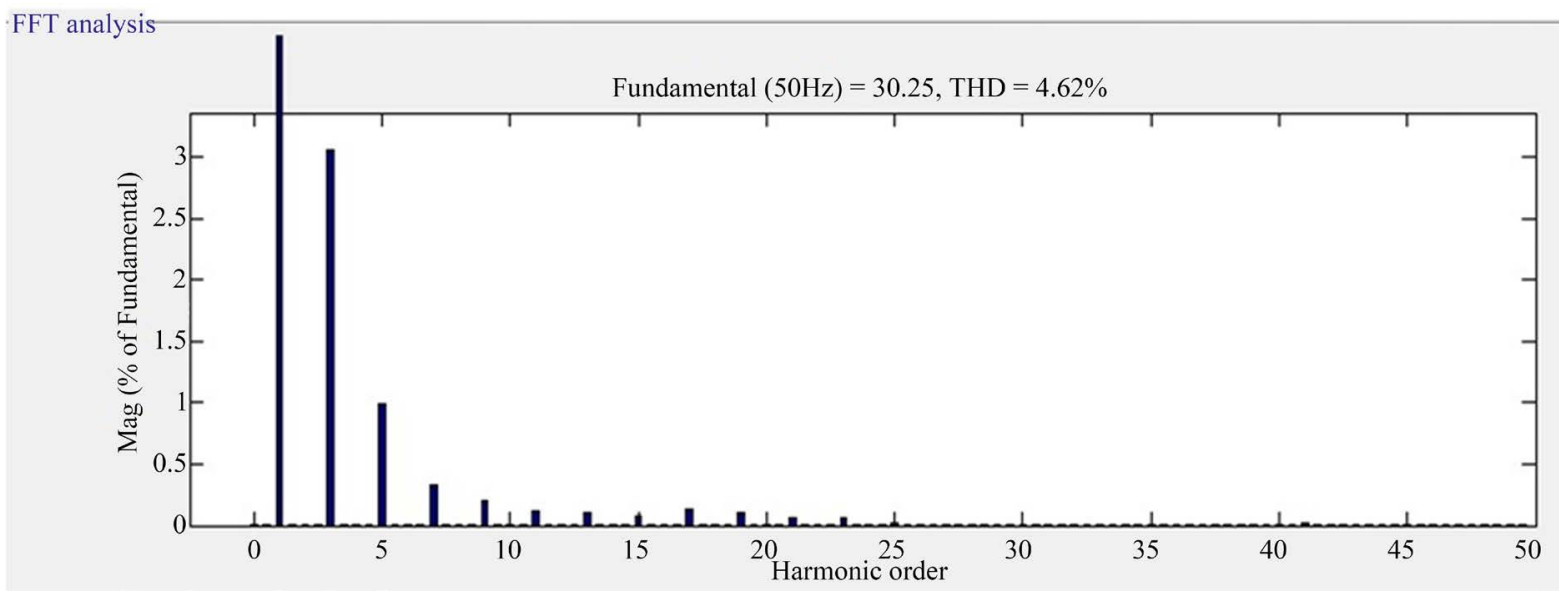

(c)

Figure 18. (a) Current Harmonics (THD) at $6 \mathrm{~m} / \mathrm{s}$ for without control strategy; (b) Current Harmonics (THD) at $6 \mathrm{~m} / \mathrm{s}$ for fuzzy control strategy; (c) Current Harmonics (THD) at $6 \mathrm{~m} / \mathrm{s}$ for proposed control strategy.

The bar chart is used to analyze the deviation of the proposed control strategy which is represented in Figure 19. In Figure 20, the current THD deviation has been compared with different control strategies. The proposed control strategy provides the current harmonics THD of $4.62 \%$, fuzzy based control strategy has provided $9.65 \%$ 


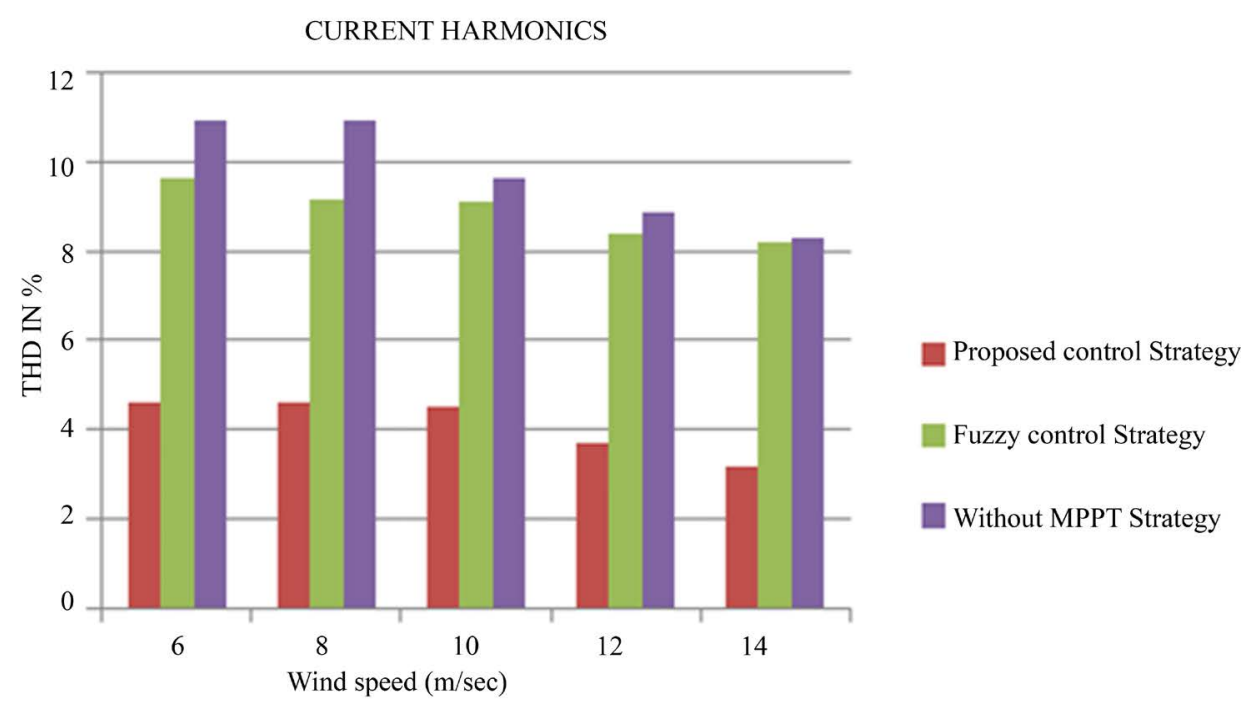

Figure 19. Current THD in percentage.

THD Deviation

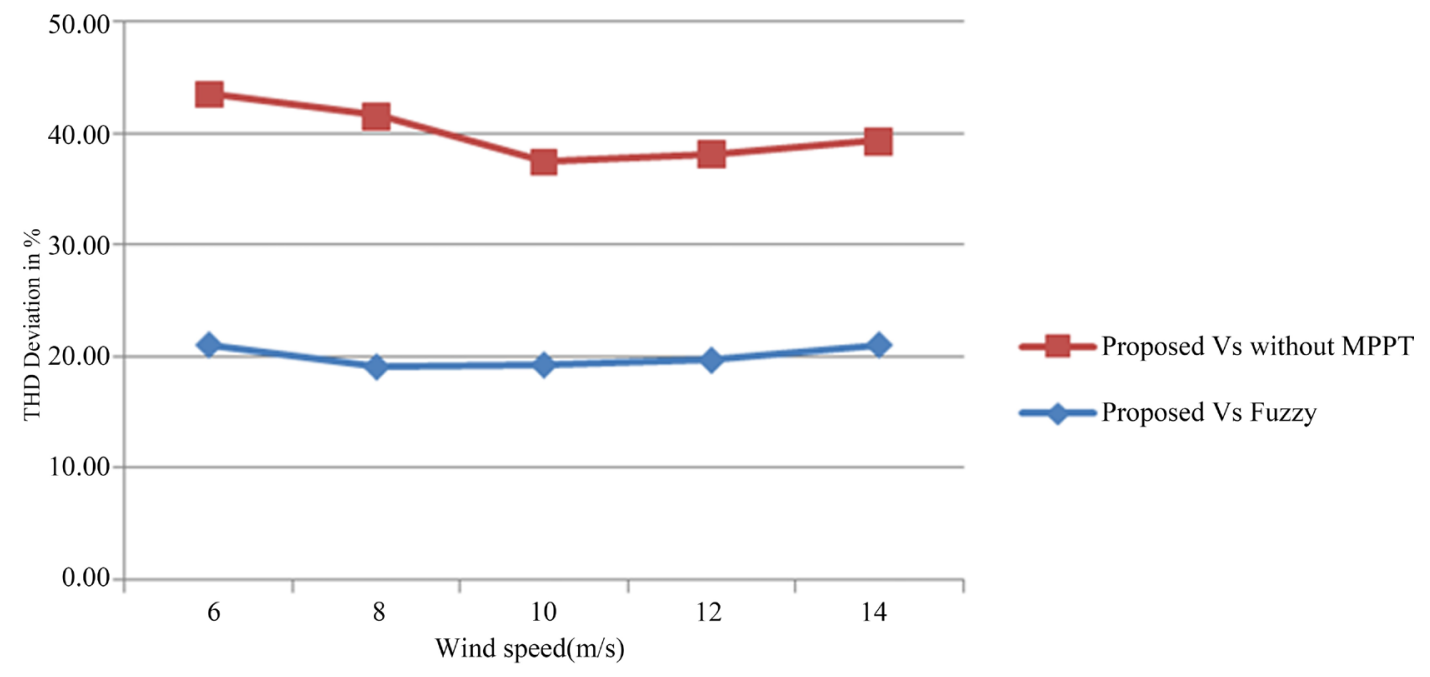

Figure 20. Current THD deviation in percentage.

and without an MPPT control strategy has provided $10.94 \%$ at a wind speed of $6 \mathrm{~m} / \mathrm{s}$. Hence, the power quality parameters of current injected into the grid connected system have drastically improved. Also, the proposed control strategy performs well at different wind speed with reduced current harmonics compared to the existing control strategy.

\section{Conclusion}

The performance of the multilevel inverter based grid-connected wind energy system has been evaluated by using the proposed ANFIS-based power extraction controlled strategy. The output current of multilevel inverter has been injected to the grid, and maximum power extracted from the wind and current harmonics have been investigated for different wind speeds. The proposed control strategy has extracted the maximum output power of $274.5 \mathrm{KW}$ with reduced current harmonics of $3.17 \%$ at a wind speed of $14 \mathrm{~m} / \mathrm{s}$. The current THD deviation of the proposed strategy has been compared with the existing control strategy. The comparative analysis highlights that the proposed control strategy has less harmonics and extracts maximum power compared to the existing control strategy. 


\section{References}

[1] Azarbara, S. and Sarvi, M. (2012) A Novel Maximum Power Point Tracking Method Based on Extension Theory for Wind Energy Conversion System. International Journal of Computer Science \& Engineering Technology (IJCSET), 3, 294- 303.

[2] Rodriguez, J., Lai, J.S. and Peng, F.Z. (2002) Multilevel Inverters: A Survey of Topologies, Controls, and Applications. IEEE Transactions on Industrial Electronics, 49, 724-738. http://dx.doi.org/10.1109/TIE.2002.801052

[3] Carrasco, J.M., Franquelo, L.G., Bialasiewicz, J.T., Galvan, E., Guisado, R.C., Prats, M.A.M., Leon, J.I. and Alfonso, N.M. (2006) Power-Electronic Systems for the Grid Integration of Renewable Energy Sources: A Survey. IEEE Transactions on Industrial Electronics, 53, 1002-1016. http://dx.doi.org/10.1109/TIE.2006.878356

[4] Steinke, J.K. and Apeldoorn, O. (2002) Applying the Experience of Industrial High Power Converter Design to Wind Power Conversion. World Wind Energy Conference \& Exhibition, Berlin, 2 July 2002, Paper PD 4-2.

[5] Erickson, R., Angkititrakul, S., Al-Naseem, O. and Lujan, G. (2004) Novel Power Electronics Systems for Wind Energy Applications: A Report. National Renewable Energy Laboratory, Subcontractor, Washington DC, Rep. NREL/ SR-500-33396.

[6] Qiao, W., Liang, J.Q., Venayagamoorthy, G.K. and Harley, R. (2011) Computational Intelligence for Control of Wind Turbine Generators. IEEE Power and Energy Society General Meeting, 5, 171-186. http://dx.doi.org/10.1109/pes.2011.6039778

[7] Dieulot, J.-Y., Chalal, L. and Colas, F. (2011) A Vibration Damping MPPT Strategy for Wind Turbines Using Delayed Feedback. IFAC Proceedings Volumes, 44, 1716-1720. http://dx.doi.org/10.3182/20110828-6-IT-1002.00339

[8] Ors, M. (2009) Maximum Power Point Tracking for Small Scale Wind Turbine with Self-Excited Induction Generator. Control Engineering and Applied Informatics, 11, 30-34.

[9] Kazmi, S.M.R., et al. (2011) A Novel Algorithm for Fast and Efficient Speed-Sensorless Maximum Power Point Tracking in Wind Energy Conversion Systems. IEEE Transaction on Industrial Electronics, 58, 29-36. http://dx.doi.org/10.1109/TIE.2010.2044732

[10] Wu, S., Wang, Y.Y. and Cheng, S.J. (2013) Extreme Learning Machine Based Wind Speed Estimation and Sensorless Control for wind Turbine Power Generation System. Neuro Computing, 102, 163-175. http://dx.doi.org/10.1016/j.neucom.2011.12.051

[11] Jeong, H.G., Seung, R.H. and Lee, K.B. (2012) An Improved Maximum Power Point Tracking Method for Wind Power Systems. Energies, 5, 1339-1354. http://dx.doi.org/10.3390/en5051339

[12] Zhu, Y., Cheng, M., Hua, W. and Wang, W. (2012) A Novel Maximum Power Point Tracking Control for Permanent Magnet Direct Drive Wind Energy Conversion Systems. Energies, 5, 1398-1412. http://dx.doi.org/10.3390/en5051398

[13] Bharanikumar, Y. and Kumar, N. (2010) Modeling and Simulation of Wind Turbine Driven Permanent Magnet Generator with New MPPT Algorithm. Asian Power Electronics Journal, 4, 52-58.

[14] Abdel-Rahim, N., Hagras, H., Zaher, M. and Ibrahim, M. (2010) Fuzzy Logic Control of Wind Energy Systems. Proceedings of the 14th International Middle East Power Systems Conference, Cairo University, Egypt, 935-940.

[15] Nangrani, S.P. (2011) Real Time Point to Point Discrete MPPT Simulation for Wind Energy System. International Journal of Advances in Electrical and Electronics Engineering, 1, 352-361.

[16] Khan, S.A., Hossain, I. and Hossain, M.J. (2011) Fuzzy Logic Based Control Scheme for Power Optimization of a Small Wind Turbine System with DC-DC Converter. International Journal of Electronics \& Communication Technology, 2, 18-21.

[17] Shukla, R.D. and Tripathi, R.K. (2012) Maximum Power Extraction Schemes \& Power Control in Wind Energy Conversion System. International Journal of Scientific \& Engineering Research, 3, 1-7.

[18] Shukla, P., Tiwari, N. and Shimi, S.L. (2015) Maximum Power Point Tracking Control for Wind Energy Conversion System: A Review. International Journal of Advanced Research in Electrical, Electronics and Instrumentation Engineering, 4, 5239-5244.

[19] Lalouni, S., Rekioua, D., Idjdarene, K. and Tounz, A.M. (2014) An Improved MPPT Algorithm for Wind Energy Conversion System. Journal of Electrical Systems, 10, 484-494.

[20] Soetedjo, A., Lomi, A. and Mulayanto, W.P. (2011) Modeling of Wind Energy System with MPPT Control. International Conference on Electrical Engineering and Informatics, Bandung, 17-19 July 2011, 1-6. http://dx.doi.org/10.1109/iceei.2011.6021836

[21] Minh, H.Q., Frederic, N., Najib, E. and Abdelaziz, H. (2011) Control of Permanent Magnet Synchronous Generator wind Turbine for Stand-Alone System Using Fuzzy Logic. Proceedings of the 7th Conference of the European Society for Fuzzy Logic and Technology, Aix-les-Bains, 18-22 July 2011, 720-727. http://dx.doi.org/10.2991/eusflat.2011.98 
[22] Arul, I., Karthikeyan, M., Krishnan, N. and Muthukumar. S. (2012) Design and Modeling Techniques for Maximum Power Optimization on Wind Electrical Power System with Variable Speed Generation Using Neuro Fuzzy. International Journal of Emerging Technology and Advanced Engineering, 2, 272-277.

[23] Lin, W.-M. and Hong, C.-M. (2010) Intelligent Approach to Maximum Power Point Tracking Control Strategy for Variable-Speed Wind Turbine Generation System. 7th International Conference on Sustainable Energy Technologies Energy, 35, 2440-2447.

[24] Mohod, S.W. and Aware, M.V. (2010) A STATCOM-Control Scheme for Grid Connected Wind Energy System for Power Quality Improvement. IEEE Systems Journal, 4, 346-352. http://dx.doi.org/10.1109/JSYST.2010.2052943

[25] Faulstich, A.J., Steinke, K. and Wittwer, F. (2005) Medium Voltage Converter for Permanent Magnet Wind Power Generators up to 5 MW. 11th European Conference on Power Electronics and Applications, Dresden, 11-14 September 2005, 1-9.

\section{Submit or recommend next manuscript to SCIRP and we will provide best service for you:}

Accepting pre-submission inquiries through Email, Facebook, LinkedIn, Twitter, etc.

A wide selection of journals (inclusive of 9 subjects, more than 200 journals)

Providing 24-hour high-quality service

User-friendly online submission system

Fair and swift peer-review system

Efficient typesetting and proofreading procedure

Display of the result of downloads and visits, as well as the number of cited articles

Maximum dissemination of your research work

Submit your manuscript at: http://papersubmission.scirp.org/ 